University of Wollongong

Research Online

Faculty of Business - Papers (Archive)

Faculty of Business and Law

$1-1-2017$

Social media adoption and use for improved emergency services operations: the case of the NSW SES

Samuel Fosso Wamba

Toulouse Business School, samuel.fosso.wamba@neoma-bs.fr

Andrew Edwards

Macquarie University

Shahriar Akter

University of Wollongong, sakter@uow.edu.au

Follow this and additional works at: https://ro.uow.edu.au/buspapers

Part of the Business Commons

Research Online is the open access institutional repository for the University of Wollongong. For further information contact the UOW Library: research-pubs@uow.edu.au 


\title{
Social media adoption and use for improved emergency services operations: the case of the NSW SES
}

\author{
Abstract \\ Despite the exponential growth of social media in emergency services design and delivery, academic \\ research and managerial practice have paid little attention to how to adopt and use it to transform \\ operations and enhance organizational performance. This paper aims to provide some insights of a \\ longitudinal case study of the adoption and use of social media technologies by the New South Wales \\ (NSW) state emergency service (SES) in Australia. The study identifies a set of internal and external \\ factors explaining the adoption and use of social media by the NSW SES including: the social media \\ bandwagon effect, the effectiveness of social media use during the January 2011 Queensland floods, the \\ NSW state strategic planning on emergency services, the opportunity offered by the upgrade of the NSW \\ SES web site, and a strong internal management leadership toward the use of social media to support \\ emergency operations. Finally, implications for research and practice are discussed.

\section{Disciplines \\ Business}

\section{Publication Details} \\ Fosso Wamba, S., Edwards, A. \& Akter, S. (2019). Social media adoption and use for improved emergency \\ services operations: the case of the NSW SES.Annals of Operations Research, 283 225-245.
}




\title{
SOCIAL MEDIA AdOPTION AND USE FOR IMPROVED EMERGENCY SERVICES OPERATIONS:
} THE CASE OF THE NSW SES

\begin{abstract}
Despite the exponential growth of social media in emergency services design and delivery, academic research and managerial practice have paid little attention to how to adopt and use it to transform operations and enhance organizational performance. This paper aims to provide some insights of a longitudinal case study of the adoption and use of social media technologies by the New South Wales (NSW) state emergency service (SES) in Australia. The study identifies a set of internal and external factors explaining the adoption and use of social media by the NSW SES including: the social media bandwagon effect, the effectiveness of social media use during the January 2011 Queensland floods, the NSW state strategic planning on emergency services, the opportunity offered by the upgrade of the NSW SES web site, and a strong internal management leadership toward the use of social media to support emergency operations. Finally, implications for research and practice are discussed.
\end{abstract}

Keywords: disaster management, emergency service, social media, Facebook, Twitter, adoption, use 


\section{Introduction}

Social media such as Facebook, Twitter and LinkedIn are emerging as new information technology (IT) tools with a tremendous potential that can help firms to achieve competitive advantage (Steininger et al. 2013). The emerging literature shows a set of evidences to this, especially the literature on social media adoption and use by large organizations such as Starbucks and Dell in the U.S., Westpac Bank in Australia (Gallaugher and Ransbotham 2011; Husin and Hanisch 2011; Sandsmark 2011). However, the history of technological innovations tells us that their ubiquitous acceptance within the business community can take a very long time. Internet adoption is a classic example. First developed in the late 1960s and early 1970s, the Internet has been widely accepted by the business community only in the 1990s, mainly because of the "change in the business perceptions of value based on the advent of fast, reliable and low cost hypertext markup language applications" (Keating et al. 2010). In addition, prior information systems (IS) studies identified a set of factors (e.g., technological, organizational and environmental factors) that will influence the acceptance rate of any given technological innovation (Jeyaraj et al. 2006; Rogers 2003; Zhu 2006). Assessing key factors explaining why a potential adopter decides to adopt or reject a given IT technological innovation in general and social medial tools in particular is an important IS research topic. Furthermore, emergency services organizations are considered as "a unique form of organization" (Fosso Wamba et al. 2012). They are in charge of responding and providing services during extreme events such as fires, floods, hurricanes, tsunamis, and other man-made and natural disasters. Emergency services encompass emergency prevention and mitigation, preparedness, response and recovery through a large number of volunteers. So far the adoption and use of ITs in general, and of social media adoption and use in particular, by organizations delivering emergency services has not yet received much attention from scholars (Fosso Wamba et al. 2012). Consequently, the main objectives of this study is to provide some insights of a longitudinal case study of the adoption and use of 
social media technologies by the New South Wales (NSW) state emergency service (SES) in Australia, with a focus on social media adoption factors. More specifically, this study seeks to answer the following research questions:

What are the key factors related to the adoption and use of social media by an emergency service operation agency?

What is the current level of use of social media tools to support emergency services operations?

In order to address these research questions, this research work draws on the extant literature on social media adoption, diffusion of innovation theory, and organizational identity, but also on the analysis of a longitudinal case study on the adoption and use of social media that was conducted within the NSW SES. Following the introduction, this paper is organized as follows. In Section 2, we provide a theoretical background to the study, clarifying concepts related to social media and introducing both the diffusion of innovation theory and the organizational identity. In Section 3, we describe the research methodology adopted for the study and which enabled us to address our research questions. Section 4 deals with the case analysis and discussion. Section 5 presents the research implications and limitations as well as some future research directions.

\section{Literature review}

\subsection{Social media adoption and use: importance of technologies and devices}

Although the literature on social media is gaining ground, a clear definition of the concept is still to be made. In this study, we adopt the definition provided by Gupta R. and Brooks (2013), which seems broader in terms of meaning. The authors define social media as "all the devices and platforms that allow users globally to virtually create and share information with 
each other" (Gupta R. and Brooks 2013). By contrast, the same authors consider that platforms refer to "virtual spaces that allow users to come together, and create and share information" (Gupta R. and Brooks 2013), while devices are "computing technologies that enable users to access the platform" (Gupta R. and Brooks 2013). Drawing on this definition, it appears that the term "social media" encompasses a range of platforms and devices (Table 1) including: social networking, media platforms, location-based services, crowdsourcing platforms, desktop computers and laptops, gaming devices and smart television, tablets, Smartphone, "dumb phones", vehicles, and augmented reality devices.

Social media platforms are considered as disruptive information technology (IT) innovations that have the capabilities of transforming the way we are currently doing business (Fosso Wamba and Carter 2013). The high interest toward social media, which is being observed in the relevant literature and within industries, is driven by many factors, including the impressive diffusion of mobile devices (e.g., mobile phones and Smartphones) to support daily operations and the pervasive use of social media tools such as Facebook and Twitter. For example, time spent on social networks began to surpass time spent with email by 2007 (Bockius 2012). Social network users surpassed the number of email users in July 2009: there were 820 million social network users, as compared to 800 million email users (Bockius 2012). More importantly, in 2011, LinkedIn added a new member every second (Bockius 2012). At the start of the year, this platform had about 80 million members. Today, that number has risen to over 500 million - and growing by five new members every second (Darrow 2017). With less than 600 million members at the onset in 2011, Facebook attracted around 1490 million active users till 2016 (Akter et al. 2016). Globally, firms are increasingly using Facebook and Twitter to co-create business value with customers (Samuel Fosso et al. 2016). Indeed, social media offer tremendous advantages as compared to traditional media. For example, social media allow spontaneous and easy multiple-way interaction with users 
(Gupta R. and Brooks 2013). They can combine transactional buying-experience information among friends and family members with real-time information related to the purchasing activities of a buyer with their friends, with the purpose of improving their shopping experiences in terms of purchasing decisions (Fisher 2011). Social media provides a new channel for improved collaboration and communication among supply chain stakeholders (Burke et al. 2010; Chan et al. 2016; Culnan et al. 2010). They may also serve to facilitate the identification of prospective business partners in the context of B2B selling (Michaelidou et al. 2011). All these characteristics may, therefore, be considered as persuading factors during the decision process for adopting and using social media.

Social media potentials have attracted the interests of firms of various sizes and sectors. For example, in reporting how large U.S. firms can use Twitter and other social media to gain business value, Akter et al. (2016,p.1) pointed out that "this massive penetration of social media paves the path for firms to derive value by capturing, understanding and presenting information on customer tastes and preferences, relationship managements, promotions, new product developments, crisis management and competitive intelligence". Culnan et al. (2010) report the example of Walmart's, which had been using a centralized social media portfolio including Twitter, Facebook applications and two blogs to mainly support the firm's branding and sales as well as engaging into community building. As for Hewlett-Packard, another example cited by (Culnan et al. 2010), the firm uses its social media portfolio formed by Twitter and Facebook applications, blogs, and hosted forums to interact with its business and customers, and to enhance customers service and support, firm branding and marketing. In the public sector, social media technologies have been used to promote changes in culture and practices in government (Picazo-Vela et al. 2011), while facilitating improved communication, participation and dialogue with the public, all of which leads to better collaboration with citizens, improved transparency and increased e-democracy (Magnusson et 
al. 2012). In addition, social media can be used by emergency service managers to monitor and respond to real time public safety issues (Kavanaugh et al. 2012), foster social resilience (Reuter and Spielhofer 2017), promote information dissemination among key emergency stakeholders (Stieglitz and Dang-Xuan 2013), and to improve overall firms' operational decisions (Cui et al. 2017). Although the extant literature shows an increased number of articles on both IT-enabled emergency services (Scholl et al. 2012) and the use of emergency technologies (e.g., RFID), very little is being written on the co-adoption or simultaneous adoption (e.g., Facebook + Twitter) and use of social media tools.

\subsection{Diffusion of innovation theory and organizational identity}

While academic studies on humanitarian operations and emergency services are increasing steadily, Oloruntoba, Hossain et al.(2016) argue that "little attention to and use of relevant theories" has been associated to this stream of research. Then, they call for an increased use of theories to deeper our understanding of various phenomenon related to humanitarian operations and emergency service. In this paper, we propose to use both the diffusion-ofinnovation and the organizational identity theories not only to explore key factors related to the adoption and use of social media by an emergency service operation agency, but also to assess the current level of use of social media tools to support such operations.

Both the diffusion-of-innovation theory and the organizational identity offer a useful theoretical outlook to analyze the rationale behind the adoption and use of social media by organizations. An innovation is typically defined as "any idea, practice, or material artifact perceived to be new by the relevant unit of adoption" (Zaltman et al. 1973). This definition is consistent with the one proposed by Rogers (2003), one of the fathers of the diffusion-ofinnovation theory for whom innovation refers to "an idea, practice, or object that is perceived as new by an individual or other unit of adoption". Innovation is considered as being at the core of economic growth (Aizcorbe et al. 2009; Porter and Millar 1985). However, the 
adoption and use of any innovation by a given organization is contingent to many factors (e.g., related to the innovation, the adopting organization and environment in which the organization is operating) (Rogers 2003). For example, Rogers (2003) theorized that innovations that are perceived as less complex by potential adopters and that have greater compatibility, trialability, relative advantage, and observability are likely to be more quickly adopted than other comparable innovations. Consequently, great attention should be paid to each of these five characteristics during the adoption process. Concerning organizational factors, early studies found that top management support, the organization's size, IT expertise, the organization's readiness, and information intensity are among important enablers of innovation adoption (Rogers 2003). With regard to environmental factors, prior studies revealed that several of them play an important role during the adoption process, especially the following: competitive pressure (Zhu et al. 2003), bandwagon innovation diffusion effect (Rosenkopf and Abrahamson 1999), and government's pressure and support (Hameed et al. 2012). Indeed, "bandwagons have a positive feedback loop in which information generated by more adoptions creates a stronger bandwagon pressure, and a stronger bandwagon pressure prompts more adoptions" (Rosenkopf and Abrahamson 1999). For example, the changing dynamics within the public sector has been putting pressure on government agencies to be innovate through the adoption and use of cutting edge technologies for improved service delivery at low cost (Naranjo-Gil 2009).

In this article, we consider that both social media and IT adoption support organizational operations as innovation. Therefore, social media's characteristics-including their possibility to allow for spontaneous interactions, their capacity to improve not only a buyer's purchasing experiences, but also collaboration and communication among supply chain stakeholders-may be considered as influencing factors during the adoption decision process. 
Tables 1: Social media technologies (Gupta R. and Brooks 2013)

\begin{tabular}{|l|l|}
\hline Platform types & Example \\
\hline Social networking & Facebook \\
\hline Friends, Groups, Events & Twitter \\
\hline Followers & Google+ \\
\hline Circles & LinkedIn \\
\hline Connections & Orkut \\
\hline Friends, Crush list, communities & \multicolumn{2}{|l|}{} \\
\hline Media platform & Youtube, SocialCam, Facebook Live \\
\hline Video & Flickr \\
\hline Photos & Instagram \\
\hline Mobile photos & \multicolumn{2}{|l|}{} \\
\hline Location-based platform & Foursquare \\
\hline Check-in & Google Latitude \\
\hline Location of circles & Find my friends \\
\hline Location of Friends & Yelp \\
\hline Local reviews and check-ins & GroupOn \\
\hline Check-in, local deals & Facebook places \\
\hline Check-in, friends location & \multicolumn{2}{|l|}{} \\
\hline Crowdsourcing platform & Amara \\
\hline Translation & Amazon's M-Turk \\
\hline Labor & Crisismappers \\
\hline Geo-location labor, verification & Crowdflower \\
\hline Labor & Reddit, Pinterest, \\
\hline Combination platform & Facebook \\
\hline Social networking, media and crowdsourcing \\
\hline $\begin{array}{l}\text { Social networking, media, location-based and } \\
\text { crowdsourcing } \\
\text { phones", vehicles and augmented reality devices }\end{array}$ \\
\hline Device types & Pair, Meebo \\
\hline Desktop computers, laptops, gaming devices, smart televisions, tablets, smartphones, “dumb \\
\hline \multicolumn{2}{|l|}{} \\
\hline
\end{tabular}

Tables 1: Social media technologies adapted from (Gupta R. and Brooks 2013)

Since our study focuses on emergency services organizations with unique characteristics (e.g., with a large number of volunteers as employees), we believe that the organizational identity theory offers a good perspective to study social media adoption within such organizations. Organizational identity is defined as the "set of beliefs shared between top 
managers and stakeholders about the central, enduring, and distinctive characteristics of an organization"(Scott and Lane 2000); it represents the "organizational members' collective understandings of the features that are presumed to be essential, distinctive, and relatively permanent about the organization" (Gal et al. 2008). Organizational identity is considered as a social construct that is shaped by firm goals, missions, practices, values and actions through constant inter-organizational reflections and comparisons with others (Colman 2008). Thus, it is worthwhile positioning organizational identity as a powerful differentiator of a given organization as compared with others (Scott and Lane 2000). Furthermore, organizational identity provided collective meanings to questions such as "who are we?" that were posed by firm members (Fiol 2001; Whetten 2006). Therefore, it serves as a key motivator that will guide the actions of firm members (Colman 2008) during the process of internalizing the cognitive structure of the aim and direction of an organization (Albert et al. 2000). That is probably why some scholars went so far to suggest that organizational identity is a firm's core competency to produce competitive advantage, notably through a contextualization and redesign of new adaptive behaviors (Fiol 2001). Consistent with observations made by Colman (2008) about organizational identity and business value creation during postacquisition integration, we believe that the adoption of social media by emergency services offers a unique setting for understanding and examining the antecedents and consequences of identity issues.

\subsection{A primer of social media for disaster management and emergency services}

Disasters may involve human or natural actions including wars, solar flares, landslides, floods, cosmic explosions and meteorites, earthquakes, tsunamis, hurricanes, droughts, and terrorist attacks (Teodorescu 2015). The number of casualties related to these disasters is increasing steadily. In 2011, for example, 332 natural disasters were recorded worldwide, causing huge human and economic impacts that were estimated, respectively, at 
244.7 million victims worldwide and US $\$ 366.1$ billion in losses (a $235 \%$ increase over the average annual losses from 2001 to 2010) (Ponserre et al. 2012), thus positioning emergency organizations at the core of disaster management policies of many countries around the world (Allen et al. 2014). Disaster management is considered as a complex task as it involves the planning and execution of multiple phases (e.g., preparedness, response, recovery, mitigation) (Sushil 2017), the coordination of multiple processes (Sushil 2017), the coordination and high-level collaboration of multiple stakeholders (e.g., local, regional or national government jurisdictions) for joint decision making and joint actions planning and execution (Chatfield et al. 2010; Coles et al. 2017; Sushil 2017), the exchange information among these key actors for improved service delivery and effective resource utilization (Altay and Pal 2014). In these high-risk environments, IT has been playing an important role. For example, Chatfield et al. (2010 argue that radio frequency identification technology and web-based geographic information systems can provide "real-time location-aware information about people and high-value assets available" during each phase of the disaster management, and thus, improving its management and coordination.

Recently, social media tools have been considered as the next IT frontier for improved disaster management (Carley et al. 2016). Indeed, social media networks offer a wide range of opportunities to transform governments' actions in terms of enhancing intra- and intergovernment agencies collaboration (Mergel 2016), creating transparency and improving accountability, enhancing collaboration and participation of citizens in the decision-making process, improving public services design and delivery (Guillamón et al. 2016)—including emergency services (Fosso Wamba and Edwards 2014). Scholars indicate that social media can be used for several other purposes: inter alia, sending alerts and identifying critical needs; enabling focus response (Carley et al. 2016); obtaining timely information (PedrazaMartinez and Van Wassenhove 2016); speeding up the collection of information about 
critical infrastructures and the population (Landwehr et al. 2016); assessing the harshness and risks of the disaster (Anson et al. 2017; Carley et al. 2016); and building community preparedness networks (Anson et al. 2017). For example, Twitter has been used to support disaster planning, warning and response (Landwehr et al. 2016). Facebook and Twitter are being constantly used to exchange and disseminate information during major crisis events (e.g., Queensland floods, Christchurch earthquakes, Japanese earthquake and tsunami, Hurricane Sandy, Haiti Earthquake) (Flew et al. 2015; Yates and Paquette 2011; Yoo et al. 2016).

\section{Methodology}

This study is part of a large study conducted within the NSW SES to assess the impact of IT on emergency service operations. The main objective of this study discussed in the paper is to enable a deep theoretical understanding of the adoption and use of social media by the NSW SES within the framework of its operations. A longitudinal case study is being adopted as the appropriate research design, and the main reason for such a choice is that it is an appropriate approach to achieve our research objectives and answer our research questions. Indeed, a case study allows for the exploration and understanding of complex phenomena within real-life settings (Eisenhardt 1989), and therefore induces theories where research and theory are still at their early and formative stages (Benbasat et al. 1987). The case study is appropriate when answering research questions such as "why" and "how" things are done (Yin 1994).

This on-going case study began in September 2011 as part of a large longitudinal study conducted within the NSW SES. This study is a result of a prior collaboration between the research team leader and the Director of ICT of the NSW SES. Indeed, the Director of ICT of the NSW SES had been presenting as a guest speaker on various topics related to enterprise systems, systems integration and innovation, as part of a subject taught by the research team leader. Afterwards, they started exploring various means of expending their collaboration. 
Thus, in September 2011, they agreed on the need to formalize a research project that would explore the impacts of various ITs on the NSW SES operations, especially for the sake of improved emergency service delivery. The last on-site visit was made in February 2017. In this study, data collection involved multiple waves (2011, 2012, 2013, 2014 and 2017) and sources of evidence such as semi-structured interviews, industrial reports, strategic planning reports, annual reports, newsletters, technical and non-technical documents, all of which allowed us to increase the validity of our constructs (Serafeimidis and Smithson 2003; Yin 1994). For example, the agency regularly publishes its strategic plan via the web site to present the roadmap for the agency direction over a five years' period of time. Also, all annual reports that discussed the agency operations, successes and challenges are published on the agency web site (https://www.ses.nsw.gov.au/about-us/publications-and-reports/). Furthermore, semi-structured interviews with key informants from various functional areas including: the Director of ICT, the manager of lessons learned, the website \& corporate profiling coordinator and the web and social media coordinator from the directorate of information and communications technology; the senior public affairs officer from the directorate of human services and four volunteers, and thus allowing us to gain deeper understanding of the use of social media within the agency (Appendix 2). Each interview lasted approximately one hour and was recorded. Subsequently, all recorded interviews were transcribed by a consulting firm. Finally, open coding analysis was realized using our target constructs. All interview questions were drawn from our literature review and our prior studies on social media adoption and use (Appendix 1). 


\section{Case analysis and discussion}

\subsection{Research site: The case of the NSW SES}

The NSW SES was constituted in April 1955 by the NSW State Government to provide emergency services within the whole NSW state, an area of approximately 800642 sq. km. This state emergency service is responsible for providing leadership and relief during tsunami, storms, floods and disasters management. In addition, the NSW SES assists various communities affected by disasters in resupplying with basic equipment and services. Furthermore, when requested, the agency may intervene and provide assistance during road crash rescue operations, vertical rescue, land search, evidence search, logistics support, and primary industries. To achieve its operations, the agency relies on a 250 paid staffs members and a large base of volunteers, about 10,000, which are divided through 229 volunteer units across the state. The NSW SES is technologically well advanced and relies on a range of IT systems to support its operations, including: about 1200 desktops and laptops, 20 servers, 800 uninterruptable power supplies, around 450 broadband modems, 246 routers \& switches, 250 network sites. Also, the agency uses a wide range of telecommunication devices for emergency services access and delivery; such equipment set encompasses about 2000 pagers, 2000 mobile phones, 300 Smartphones, 4200 radios and 170 satellite phones.

\subsection{Social media adoption and use: key drivers and levels of usage}

\subsubsection{Key drivers for the adoption and use of social media}

The NSW SES started investigating the potential of social media for emergency service delivery in the early July 2008 mainly because of the joint effects of both internal and external factors. External factors include the social media bandwagon effect, the effectiveness of social media use during the January 2011 Queensland floods and the NSW state strategic planning on emergency services (NSW Government 2011). Indeed, in this planning, the 
NSW state government had among its top priorities the need to increase volunteering and prepare the state to be ready to deal with major emergencies and natural disasters. Thus, the state had been promoting the use of cutting edge technologies to achieve these objectives. In addition, the management board of the NSW SES was aware of the successful use of social media (e.g., Twitter and Facebook) by key Queensland emergency service agencies during the January floods, as they really helped to provide real-time information to citizens and therefore contributed to locating survivors and saving lives. As stated by Hamm (2012), "of all social media platforms, Twitter and Facebook have been identified as the most prolific source of immediate information throughout the Queensland floods. Facebook's role was also significant, with the Queensland Police Service's Facebook page exploding to a staggering 165,000 during the peak of the crisis. Between 10 January and 16 January 2011, more than 35,000 tweets tagged \#qldfloods were posted by more than 15,000 individual users. Peak activity occurred around noon on 11 January 2011 with approximately 1,100 tweets per hour being sent as the Brisbane River overflowed its banks. On 12 January, nearly 7,000 twitter users either posted original or retweeted information. Of the information shared, $50-60 \%$ were retweets while $30-40 \%$ consisted of web links to further information."

The main internal factors were the opportunity offered by the upgrade of the NSW SES web site and a strong internal management leadership geared toward the use of Its, including social media, to support emergency operations. Indeed, in October 2008, the agency decided to upgrade its entire web site infrastructure. At that time, the management board had started discussing with various service providers about the opportunity to integrate emerging social media platforms into the new web site. However, the discussion was unsuccessful for a number of reasons: the lack of understanding of the real business value of social media for the agency, the lack of strategic direction by the NSW State Government, the parent organization, the lack of social media policy at the agency and state levels, and the paucity of 
resources for the agency to support its initiative. This is well illustrated by the NSW SES Director of ICTs comments:

"At the time, [that is, in October], we were upgrading our website. And as part of that, we were discussing with the service providers about opportunities to integrate social media into the website because there were actually not a lot of people doing it at that point in time. So do you remember doing any of that several years back? That is what we commonly see now on every website. There weren't many social media sites running around as it is the case today. But for one reason or another, we actually decided at that point in time that we didn't want to go anywhere near social media because it was just too much of a scary beast and we didn't understand what it meant for the organization. In fact, looking outside the organization, I think that was at that point in time, the government in particular was not going to, or didn't want to engage in anything in relation with social media because they didn't understand it or know what it actually meant."

More specifically, the exploration of the business value related to social media for emergency service delivery by the NSW SES is in line with these internal and external drivers. With regard to the internal management leadership, the NSW SES board is aware of the high strategic and operational potential of social media in managing emergency operations. Thus, it has taken a couple of actions toward the materialization of the adoption and effective use of social media within the agency, including (see Table 3): the creation of a social media group to explore, amongst other things, the potential of social media and the formulation of policies that will guide their use within the agency. This is consistent with prior studies on IT adoption and use which highlight the importance of strong management leadership during the IT adoption process. Emerging literature on social media adoption and use also found similar patterns. In a recent survey study by (Kiron et al. 2012) about what managers really think about social business, they found that " $70 \%$ of CEOs (along with presidents and managing 
directors) and CIOs in our survey believe that social business will be important to their organization in three years". In addition, the authors found that: (i) "clear vision for how social media supports business strategy", and (ii) "senior management support" were the top two facilitating factors of the adoption of social platforms within organizations. Also, they identified that the "lack of management understanding" was the top internal barrier to the adoption of social media by an organization. This clearly indicates the importance of highlighting strong management leadership toward the adoption and effective use of social media within organizations.

Table 2 The NSW SES technological developments within the social media landscape

\begin{tabular}{|c|c|c|c|c|}
\hline & $\begin{array}{c}\text { Not aware of } \\
\text { this }\end{array}$ & $\begin{array}{c}\text { Do not have, } \\
\text { but aware }\end{array}$ & $\begin{array}{c}\text { Have but do } \\
\text { not regularly } \\
\text { use }\end{array}$ & $\begin{array}{l}\text { Have and regularly } \\
\text { use to support our } \\
\text { operation }\end{array}$ \\
\hline \multicolumn{5}{|l|}{ Social networking } \\
\hline Facebook & & & & $\mathrm{X}$ \\
\hline Twitter & & & & $\mathrm{X}$ \\
\hline Google+ & & $\mathrm{X}$ & & \\
\hline LinkedIn & & & $\mathrm{X}$ & \\
\hline \multicolumn{5}{|l|}{ Media platform } \\
\hline Youtube & & & & $\mathrm{X}$ \\
\hline Flickr & & & & $\mathrm{X}$ \\
\hline Instagram & & $\mathrm{X}$ & & \\
\hline Periscope & & & & $\mathrm{X}$ \\
\hline Facebook Live & & & & $\mathrm{X}$ \\
\hline SocialCam & $X$ & & & \\
\hline \multicolumn{5}{|c|}{ Location-Based platform } \\
\hline Foursquare & & $\mathrm{X}$ & & \\
\hline Google Latitude & & $\mathrm{X}$ & & \\
\hline Find my friends & & $\mathrm{X}$ & & \\
\hline Yelp & & $\mathrm{X}$ & & \\
\hline GroupOn & & $\mathrm{X}$ & & \\
\hline Facebook places & & & $X$ & \\
\hline \multicolumn{5}{|c|}{ Crowdsourcing platform } \\
\hline Amara & $\mathrm{X}$ & & & \\
\hline Amazon’s M-Turk & $\mathrm{X}$ & & & \\
\hline Crisismappers & $\mathrm{X}$ & & & \\
\hline Crowdflower & $\mathrm{X}$ & & & \\
\hline
\end{tabular}




\subsubsection{The early adoption and use phase: Focus on Facebook for community engagement}

After this initial investigation, the agency conducted a thorough analysis of both its ability to start a robust social media portfolio implementation for emergency service delivery and the required resources to run it. Subsequently, a group of NSW SES members started conducting research on various internal and external key stakeholders who adopted social media. The same group also attended meetings and conferences organized by other state emergency services agencies on the adoption and use of social media and capitalized on the key lessons learned. Afterwards, in December 2009, the NSW SES started working on a Social Networking Policy that would govern the use of social media by all the agency's key stakeholders.

As a result, the agency decided to focus not only on Facebook (see Table 2 and Table 3), but also on Youtube (Table 3) for community engagement (e.g., general community safety information, talking about activities that could be carried on across the organization and at the state level). For the NSW SES, "social media is about community engagement, volunteers' recruitment and firm differentiation as we engage our staffs and volunteers around technology", highlights the NSW SES Director of ICTs. This observation is shared by the Website \& Corporate Profiling Coordinator, who adds that, for a given community, "we focus on when we know something is definitely going to impact them mentioning them specifically just so they know that we know they exist." 
Table 3: Social media usage for emergency services delivery at the NSW SES

\begin{tabular}{|c|c|}
\hline Phases & Contributions of social media at the NSW SES \\
\hline $\begin{array}{l}\text { Prevention \& } \\
\text { Mitigation }\end{array}$ & $\begin{array}{l}\text { 1. Social media for community engagement: } \\
\text { 1.1.By providing important information to citizens on how to prevent } \\
\text { and mitigate potential disasters } \\
\text { 1.2.By pushing important safety messages to: } \\
\begin{aligned} \text { 1.2.1. } & \text { Deliver community service announcements } \\
\text { 1.2.2. } & \text { Improve brand recognition and acknowledgement of } \\
& \text { volunteers' workforce (e.g. showcase volunteers) } \\
\text { 1.2.3. } & \begin{array}{l}\text { Provide detailed information on localized community } \\
\text { engagement events (e.g. School visits, agriculture }\end{array} \\
& \text { fairs, conference presentations) } \\
\text { 1.2.4. } & \text { Coordinate all NSW SES Social Media Administrators } \\
\text { 1.2.5. } & \text { Engage in online discussions and polls }\end{aligned} \\
\end{array}$ \\
\hline Preparedness & $\begin{array}{l}\text { 2. Social media for improved disaster preparedness: } \\
\text { 2.1.By sharing information from warning messages: } \\
\text { 2.2.By providing important information to citizens on how to } \\
\text { prepare for potential disasters } \\
\text { 2.3.By linking to other related information on social media or other } \\
\text { websites } \\
\text { 2.4.By pushing important safety messages }\end{array}$ \\
\hline Response & $\begin{array}{l}\text { 3. Social media for improved disaster response: } \\
\text { 3.1.By providing media information on significant jobs to direct } \\
\text { enquiries } \\
\text { 3.2.By sharing real-time operational information about the number } \\
\text { of jobs in terms of: What needs to be done, What has to been } \\
\text { done, and What still needs to be done } \\
\text { 3.3.By sharing important information about the number of } \\
\text { volunteers the agency has in the field for the event. } \\
\text { 3.4.By pushing important safety messages } \\
\text { 3.5.By providing links to important information about roads to } \\
\text { avoid because of bad traffic conditions and information from } \\
\text { the Bureau of Meteorology } \\
\text { 3.6.By providing direct information concerning evacuations or } \\
\text { isolations } \\
\text { 3.7.By Providing visualization of response activities through Maps, } \\
\text { Images and videos on a } 7 \text { day, } 24 \text { hours or } 3 \text { hours rotation } \\
\text { depending on the severity of the disaster } \\
\text { 3.8.By Engaging in intelligence gathering from the community on } \\
\text { the scope of the disaster by using discussions and imagery } \\
\text { 3.9.By Communicating directly with the community to dispel } \\
\text { myths and rumors concerning the disaster }\end{array}$ \\
\hline Recovery & $\begin{array}{l}\text { 4. Social media for improved disaster recovery: } \\
\text { 4.1.By providing links on recovery information including recovery } \\
\text { centers, Where to get help, How to help yourself, and How to } \\
\text { better prepare for next time. }\end{array}$ \\
\hline
\end{tabular}


Since commencing the study in 2012, NSW SES policies and strategies in relation to social media were updated in 2015. The updates provide several principles to be adopted by the organization in using social media for both personal and corporate use to engage with the community in preparing for and responding to emergencies and disasters. The policy principles outlined in the corporate use of social media provides guidance on how it is to be used during operational and non-operation periods, authorization to establish additional accounts, naming, management, decommissioning and the privacy of information. The principles identified in the personal use of social media cover privacy, public comment, postings, legal liability and monitoring. These policies have been implemented in response to issues that have occurred within the social media sphere to provide guidance to the organization as a whole and individuals on what is an expected standard of management and comment. Of interest is the establishment of a significant number of open and closed groups across the Facebook and Twitter social media platforms. Instead of the one primary social media site (on Facebook), a significant number of local community based sites have been created based on townships/local government areas and are maintained by the local volunteer SES Units. The purpose of these sites is to enable the local SES Volunteer Units to communicate public safety messages directly to their local community. All these policy principles were confirmed in 2017. Also, in 2016 the agency expanded its human resources capabilities by opening a new position entitled 'Digital Media Officer' within the social media unit to facilitate the creation of rich content (e.g., videos) for social media and support for internal communications related projects (NSW SES 2016).

\subsubsection{Extending the exploitation of social media tools: Consolidating the Facebook use and link to Twitter}

In early 2010, the agency's Facebook account was linked to its Twitter account to allow automatic posting of Tweets on the firm's Facebook wall. Later in February 2011, the NSW 
SES Social Networking Policy was born. The document provides guidelines on social media use within the agency, including (NSW SES 2011): acceptable work-related uses of social networks, members' privacy management, use of photography and audiovisuals, and the types of social networking that may be relevant for the NSW SES (e.g., Facebook, Twitter, Youtube/Flick, LinkedIn, Blogs/Forums). For example, it was acceptable to use social media for the following work-related purposes: use of public social networks (i) for recruiting purposes, (ii) to monitor public opinion about the NSW SES, its products and services, (iii) to create affinity groups to support agency marketing and communication goals, or to obtain testimonials, and (iv) for professionals networking processes (see Table 3 for more details). One key issue faced by the agency was the level of interaction with the public using social media, especially Facebook. This preoccupation had been clearly expressed by the NSW SES Director of ICTs: "we looked at it and just could not do it as a one-way communication site, which would defeat the purpose of social media. Do we have some limited interactions with the public or do we go fully fledged out there? Let's put stuff out there, and take comments back in. We can end up with a hybrid model from those various recommendations." Indeed, prior studies on social media interactions with firms' key stakeholders have identified various possible patterns of interactions. For example, Gallaugher and Ransbotham (2011) conceptualized an interaction between firms and customers using social media in terms of a (3-M) framework: megaphone or a firm-to-customer communication, magnet that represents the customer-to-firm communication, and monitor or the customer-to-customer interaction. For example, in the event of a given disaster event, the agency opened up a Facebook page on which anybody could put anything. More specifically, the social media group can post relevant written messages, icon-based messages, and visuals that people can comment, but they can't start a new thread themselves. The agency was also using social media for operation purposes. They ranged from providing relevant information about field jobs for 
volunteers with descriptions of such jobs' locations to visits of VIP authorities on the fields of operations. As the website \& corporate profiling coordinator said, "we informed them [volunteers] of the locations of jobs, showing them how they could get images or some vision of any description. And we were having VIPs visiting the area. There were information about the number and types of jobs coming through, the statistics, and about how many had been completed, how many were outstanding, the most impacted areas. You have to know how the weather out looks like, when the situation is likely to clear, what the Bureau of Meteorology is advising, how many volunteers we have got out and about and where they are coming from, and crews from other areas."

When adopting social media, decisions governing the choice of the best infrastructure and related governance responsibilities are considered as fundamental. Indeed, "governance is an essential component of an organization's social media strategy and deserves considerable attention" (Candace Deans 2011). For example, Culnan et al. (2010) suggest that in order to capture full business value from social media, firms need to develop implementation strategies based on three elements: mindful adoption, community building, and absorptive capacity. Among sound adoption decisions, they identified the five following critical elements: making a good decision about which platform(s) to adopt and how they should be used, assigning responsibility for governance and identifying metrics to measure value, making sure all applications are readily accessible and managing risks.

With regard to the NSW SES, the decision has been clearly to focus on Facebook at the early stage, and then consolidate with the use of others social media tools including Twitter (Table 2). Also, the NSW SES opts for a centralized infrastructure that is managed from the firm headquarters by a dedicated team of six members led by a web and social media coordinator. However, an authority is given to specific people also called administrators within the 229 volunteer units across the state to manage social media content related to their specific unit; 
so they are empowered (see Table 3). The web and social media coordinator proudly states: "That is SES-related. (...) other people are allocated to actually take control of it and they have the full responsibility of that page to, you know, do the content, make sure it is spelled correctly; and all of that type of stuff'. For example, a Facebook group was created to ensure the coordination between various administrators of the NSW SES Facebook pages across the state with the aim of facilitating knowledge acquisition and sharing among them (Table 3). The platform is also used to solve potential issues related to the use of social media within their unit. Talking about this Facebook group, the web and social media coordinator emphasized that, "if a comment comes up or if something that they [administrators] have an issue with and they [administrators] want to talk about it, they [administrators] put it up there and then everyone puts their input and we just work out a way to resolve it. And sometimes, they say: 'oh; I found this post, should I put it up'. And I have a look at it and then everyone is like: 'yes', 'no', depending on it, we come to a decision'. The choice of a centralized infrastructure to manage its social media portfolio is in line with the NSW SES organizational identity. Indeed, the agency manages its core emergency processes from its headquarters with a strong support of its network of volunteer units across the state.

This governance mechanism ensures that the agency is meeting its objectives in terms of social media use. For example, the NSW SES deputy commissioner requires that the social media group posts a minimum number of two posts (one in the morning and another one in the afternoon) on the Facebook and few tweets as well during a general day-to-day business. With an average of one post per hour and then further updates as required during operational time (e.g., floods, storms). Usually, during high operational time there will be a dedicated person at the headquarters working on social media and website in order to update these platforms in real time, and thus ensuring a constant interaction with key stakeholders (Table 3). These intense activities can be viewed in the number of statistics captured during normal 
day-to-day activities and operational periods. More importantly, the agency now has the ability to share and update in real-time all weather information obtained from the Weather Bureau, and thus improving inter-agency information flow and sharing emergency response. It is not surprising that the NSW SES Director of ICTs posits: "We would only post information from the weather bureau directly from briefings that we had in front of us. We did sit in the briefings and we were tweeting during the briefings as we found out new information because, traditionally, you have to wait until the end of the briefing; then you write a web story and send it out, so we thought we will try doing it - plus you know, with the press conferences just straight from. There wasn't a huge amount of interest in what we were putting out."

In 2016, the agency added new social media initiatives including 'Flickr', 'Facebook Live' and 'Periscope'(NSW SES 2016). During the critical incidents happened in 2015, 2016 and 2017 , the agency successfully used social media tools to provide the community with realtime updates on safety and preparedness information in order to ensure "safer, better prepared and informed communities'. For example, the agency 'Facebook Live' and 'Periscope' were used to provide real-time updates on NSW SES operational responses (NSW SES 2016). In the same year, the agency sustained its use of social media for online community engagement that was translated for example by an impressive level of Facebook likes $(100,000)$.

Table 2 provides an overview of key social media technologies that are currently in used within the NSW SES. It also presents the firm level of awareness of the most important media platforms, social networking tools and location-based platform as defined by (Gupta R. and Brooks 2013). The table confirms the intensive use by the NSW SES of two social networking tools: Facebook and Twitter and media platform: Youtube, Periscope and Facebook Live. The agency also has a limited use of LinkedIn and Facebook Places. While 
the NSW SES doesn't have, but is aware of much of the location-based platforms, it is not aware of any of the major existing crowdsourcing platforms. Table 3 provides the overall contribution of social media tools in support of emergency operations within the NSW SES.

\subsubsection{Future of social media within the NSW SES}

The NSW SES board is already exploring future use of social media tools within the agency for increasingly improved emergency service delivery. In addition to connecting the social media portfolio to the firm's existing IT infrastructure for the sake of improvement, the agency is currently working toward developing services that can be delivered to various types

of devices (e.g., laptops, tablets, and smartphones). Also, the agency is currently exploring the way of developing internal analytic capabilities in order deal with the surge of social media data. The agency is also exploring how the integrated IT-infrastructure will facilitate internal decision making process with regard to the management of key disaster management phases. Finally, the NSW SES is exploring how social media use at the agency level can contribute to overall NSW state government objective of promoting a transparent and open government.

\section{Implications and future research directions}

\subsection{Summary of findings}

We have conducted a longitudinal case study on the adoption and use of social media by the NSW SES, focusing on the identification of the set of internal and external factors explaining how and why the agency decided to integrate the technology. Among the enabling factors, the social media bandwagon effect, the effectiveness of social media use during the January 2011 Queensland floods, March 2017 cyclone Debbie and the NSW state strategic planning on emergency services were identified as key external ones, while the opportunity offered by the upgrade of the NSW SES web site and a strong internal management leadership toward the 
use of social media to support emergency operations appeared as key internal factors for social media adoption and use by the NSW SES. Also, the analysis of this longitudinal case study has identified the NSW SES technological developments within the social media landscape. For example, the NSW SES is currently using intensively two social networking tools, namely Facebook and Twitter, as well as other platforms: YouTube, Periscope and Facebook Live. The agency has a limited use of LinkedIn. The results of this case study contribute to the stream of research on the diffusion-of-innovation theory and are evident of a practical application of the organizational identity concept during the adoption of social media. Indeed, a specific organizational identity is critical when choosing the appropriate IT infrastructure that will support social media's selected portfolios, as is a governance mechanism to ensure its successful adoption.

\subsection{Theoretical and managerial contributions}

The findings of the study contribute to the literature across operations, information systems, and marketing disciplines. By introducing social media to emergency services, we put forward the dynamic nature of social media adoption, use and continuance. Thus, we stress that social media, as a dynamic capability, serves simultaneously at operational, technological and communication levels of an organization to meet emergency service delivery needs. That is, social media can accelerate the service delivery processes, interact with customers and adapt with the changing needs to redesign the supply chain. This illustrates the reflection and extension of dynamic capability theory through the agile nature of social media in tackling risks and uncertainty in the domain of emergency services management (Teece et al. 2016). The findings of our study also extend IT productivity literature because social media plays a significant role in enhancing performance, thus adoption of this platform and relevant investments can contribute to organizational transformation (Pan et al. 2015). As such, various social media platforms should be prioritized by managers in allocating IT budgets 
according to its ability to generate financial value. With regard to adoption, our study has distilled the critical factors (e.g., perceived usefulness, ease of use, social influence, facilitating conditions) and contingencies related to both the organizational and user contexts in adopting and continuing social media for emergency service organizations. In the context of marketing, social media engagement metrics can help emergency service organizations in responding to the community in needs at the right time and right place. Since social media involves millions and it creates a virtual ecosystem via online communities, blogs, discussion forums and virtual worlds, customer value co-creation is another exciting avenue for research through real time connection and collaboration. Emergency service organizations can draw solid insights for service innovation from this deep, diverse knowledge pool. Furthermore, social media provides the platform for social learning to consumers through the content creation and content transmission behavior.

The findings of our study provide managers with some key guidelines on how to enhance adoption and use of social media for emergency services. First, we stress on embedding personalization features to engage with users or community by communicating the sense of personal care or belongingness. Second, we recommend that managers should focus on the content and relationship aspects while designing their platforms in order to facilitate content creation and transmission as well as relationship building and maintenance. These are critical aspects to grow and continue relationships, encourage user generated content and increase the frequency of visits and traffic. Third, we argue for embracing organizational ambidexterity to explore and exploit social media through long term commitments to specialized resources. Overall, we suggest emergency service organizations applying different strategies and design principles for developing social media sites with individual and group applications for right time engagement with the community in needs. 


\subsection{Limitations and future research directions}

Some of the limitations need to be acknowledged. Although the case study approach is appropriate when exploring emerging concepts (e.g., adoption and use of social media to support emergency operations) for theory development, the approach holds some limitations which include: difficulties in generalizing research findings, the subjectivity of the data collection as well as analysis processes (Darke et al. 1998). Future research should look at how to integrate social media portfolio into existing intra-and inter-agencies IT infrastructure for information sharing, collaboration and coordination during disaster events. Ansell et al. (2010) found that inter-jurisdictional coordination (e.g., between cities, between different government agencies levels-state vs. national) and inter-sectoral coordination are the two most important challenges in organizing a response during disaster events. Therefore, exploring how social media tools can enhance these two types of coordination should also be included into future research directions. Indeed, emergency service response involves "multiple organisations collecting, collating and communicating data and information that support resource allocation decisions to minimise social and economic impacts. In order to act in a coordinated and effective way, organisations require access to information characterising the disaster's intensity, location and related damages, as well as the availability of human and physical resources. Such information can originate from multiple organisations" (Dantas and Seville 2006). Therefore, developing mechanisms to facilitate information sharing from social media across emergency services should be included into future research direction. How to analyze big data generated by social media tools for improved decision making should also be incorporated in future research. Addressing important concerns by community regarding security and privacy issues of social media for emergency service delivery can also be a part of future investigation. 


\section{References}

Aizcorbe, A. M., Moylan, C. E., and Robbins, C. A. 2009. "Toward Better Measurement of Innovation and Intangibles," Bureau of Economic Analysis (89:1), pp. 10-23.

Akter, S., Bhattacharyya, M., Wamba, S. F., and Aditya, S. 2016. "How Does Social Media Analytics Create Value?," Journal of Organizational and End User Computing (JOEUC) (28:3), pp. 1-9.

Albert, S., Ashforth, B. E., and Dutton, J. E. 2000. "Organizational Identity and Identification: Charting New Waters and Building New Bridges," Academy of Management Review (25:1), pp. 13-17.

Allen, D. K., Karanasios, S., and Norman, A. 2014. "Information Sharing and Interoperability: The Case of Major Incident Management," European Journal of Information Systems (23:4), pp. 418-432.

Altay, N., and Pal, R. 2014. "Information Diffusion among Agents: Implications for Humanitarian Operations," Production and Operations Management (23:6), pp. 10151027.

Ansell, C., Boin, A., and Keller, A. 2010. "Managing Transboundary Crises: Identifying the Building Blocks of an Effective Response System," Journal of Contingencies and Crisis Management (18:4), pp. 195-207.

Anson, S., Watson, H., Wadhwa, K., and Metz, K. 2017. "Analysing Social Media Data for Disaster Preparedness: Understanding the Opportunities and Barriers Faced by Humanitarian Actors," International Journal of Disaster Risk Reduction (21), pp. 131-139.

Benbasat, I., Goldstein, D. K., and Mead, M. 1987. "The Case Research Strategy in Studies of Information Systems," MIS Quarterly (11:3), pp. 369-386.

Bockius, C. 2012. "2012 Is the Year for Firm-Wide Adoption of Social Media ".

Burke, W. Q., Fields, D. A., and Kafai, Y. B. 2010. "Entering the Clubhouse: Case Studies of Young Programmers Joining the Online Scratch Communities," in: Journal of Organizational and End User Computing. p. 21+.

Candace Deans, P. 2011. "The Impact of Social Media on C-Level," MIS Quarterly Executive (10:4), pp. 187-200.

Carley, K. M., Malik, M., Landwehr, P. M., Pfeffer, J., and Kowalchuck, M. 2016. "Crowd Sourcing Disaster Management: The Complex Nature of Twitter Usage in Padang Indonesia," Safety Science (90), pp. 48-61.

Chan, H. K., Wang, X., Lacka, E., and Zhang, M. 2016. "A Mixed-Method Approach to Extracting the Value of Social Media Data," Production and Operations Management (25:3), pp. 568-583.

Chatfield, T. A., Fosso Wamba, S., and Tatano, H. 2010. "E-Government Challenge in Disaster Evacuation Response: The Role of Rfid Technology in Building Safe and Secure Local Communities," The 43rd Hawaii International Conference on System Sciences, Koloa, Kauai, Hawaii, pp. 1-10.

Coles, J. B., Zhang, J., and Zhuang, J. 2017. "Bridging the Research-Practice Gap in Disaster Relief: Using the Ifrc Code of Conduct to Develop an Aid Model," Annals of Operations Research), pp. 1-21.

Colman, H. L. 2008. "Organizational Identity and Value Creation in Post-Acquisition Integration: The Spiralling Interaction of the Target's Contributive and the Acquirer's Absorptive Capacities," in: Strategy and Logistics. Oslo: BI Norwegian School of Management, p. 260.

Cui, R., Gallino, S., Moreno, A., and Zhang, D. J. 2017. "The Operational Value of Social Media Information," Production and Operations Management), pp. n/a-n/a. 
Culnan, M. J., McHugh, P. J., and Zubillaga, J. I. 2010. "How Large U.S. Companies Can Use Twitter and Other Social Media to Gain Business Value," MIS Quarterly Executive (9:4), pp. 243-259.

Dantas, A., and Seville, E. 2006. "Organisational Issues in Implementing an Information Sharing Framework: Lessons from the Matata Flooding Events in New Zealand," Journal of Contingencies and Crisis Management (14:1), pp. 38-52.

Darke, P., Shanks, G., and Broadbent, M. 1998. "Successfully Completing Case Study Research: Combining Rigour, Relevance and Pragmatism," Information Systems Journal (8:4), pp. 273-289.

Darrow, B. 2017. "Linkedin Claims Half a Billion Users." from http://fortune.com/2017/04/24/linkedin-users/

Eisenhardt, K. M. 1989. "Building Theories from Case Study Research," Academy of Management Review (14:4), pp. 532-550.

Fiol, C. M. 2001. "Revisiting an Identity-Based View of Sustainable Competitive Advantage," Journal of Management (27:6), pp. 691-699.

Fisher, L. 2011. "The Key Trends in Social Commerce." Retrieved June 27, 2011, from http://thenextweb.com/socialmedia/2011/03/08/the-key-trends-in-social-commerce/

Flew, T., Bruns, A., Burgess, J., Ben-Harush, O., Potter, E., and Newton, J. 2015. "Support Frameworks for the Use of Social Media by Emergency Management Organisations," Digital Media Research Centre, Centre for Emergency and Disaster Management, Queensland University of Technology, p. 24.

Fosso Wamba, S., and Carter, L. 2013. "Social Media Tools Adoption and Use by Smes: An Empirical Study," Journal of End User and Organizational Computing (XX:XX), pp. XX-XX.

Fosso Wamba, S., Edwards, A., and Sharma, R. 2012. " 'Big Data' as a Strategic Enabler of Superior Emergency Service Management: Lessons from the New South Wales State Emergency Service," in: ICIS 2012 MIS Quarterly Executive Workshop. Orlando, USA.

Fosso Wamba, S., and Edwards, A. J. 2014. "Factors Related to Social Media Adoption and Use for Emergency Services Operations: The Case of the Nsw Ses," in: 20th Americas Conference on Information Systems. Savannah, Georgia, USA.

Gal, U., Lyytinen, K., and Yoo, Y. 2008. "The Dynamics of It Boundary Objects, Information Infrastructures, and Organisational Identities: The Introduction of $3 \mathrm{~d}$ Modelling Technologies into the Architecture, Engineering, and Construction Industry," European Journal of Information Systems (17), pp. 290-304.

Gallaugher, J., and Ransbotham, S. 2011. "Social Media and Customer Dialog Management at Starbucks," MIS Quarterly Executive (4), pp. 197-212.

Guillamón, M.-D., Ríos, A.-M., Gesuele, B., and Metallo, C. 2016. "Factors Influencing Social Media Use in Local Governments: The Case of Italy and Spain," Government Information Quarterly (33), pp. 460-471.

Gupta R., and Brooks, H. 2013. Using Social Media for Global Security. Indianapolis: John Wiley \& Sons, Inc. .

Hameed, M. A., Counsell, S., and Swift, S. 2012. "A Conceptual Model for the Process of It Innovation Adoption in Organizations," Journal of Engineering and Technology Management (29:3), pp. 358-390.

Hamm, B. 2012. "The Police, Social Media and the Queensland Floods." Retrieved June 1, 2013, from http://www.smk.net.au/article/the-police-social-media-and-thequeensland-floods

Husin, M. H., and Hanisch, J. 2011. "Utilising the Social Media and Organisation Policy (Someop) Framework: An Example of Organisational Policy Development within a 
Public Sector Entity," 19th European Conference on Information Systems V. Tuunainen, J. Nandhakumar, M. Rossi and W. Soliman (eds.), Helsinki, Finland, pp. 3096-3107.

Jeyaraj, A., Rottman, J. W., and Lacity, M. C. 2006. "A Review of the Predictors, Linkages, and Biases in It Innovation Adoption Research," Journal of Information Technology (vol. 21:no. 1), pp. pp. 1-23.

Kavanaugh, A. L., Fox, E. A., Sheetz, S. D., Yang, S., Li, L. T., Shoemaker, D. J., Natsev, A., and Xie, L. 2012. "Social Media Use by Government: From the Routine to the Critical," Government Information Quarterly (29:4), pp. 480-491.

Keating, B. W., Coltman, T. R., Fosso-Wamba, S., and Baker, V. 2010. "Unpacking the Rfid Investment Decision," Proceedings of the IEEE (98:9), pp. 1672-1680.

Kiron, D., Palmer, D., Phillips, A. N., and Kruschwitz, N. 2012. "What Managers Really Think About Social Business," MIT Sloan Management Review (53:4), pp. 51-59.

Landwehr, P. M., Wei, W., Kowalchuck, M., and Carley, K. M. 2016. "Using Tweets to Support Disaster Planning, Warning and Response," Safety Science (90), pp. 33-47.

Magnusson, M., Bellström, P., and Thoren, C. 2012. "Facebook Usage in Government - a Case Study of Information Content," 18th Americas Conference on Information Systems (AMCIS 2012), Seattle, Washington, USA, pp. 1-10.

Mergel, I. 2016. "Social Media Institutionalization in the U.S. Federal Government," Government Information Quarterly (33:1), pp. 142-148.

Michaelidou, N., Siamagka, N. T., and Christodoulides, G. 2011. "Usage, Barriers and Measurement of Social Media Marketing: An Exploratory Investigation of Small and Medium B2b Brands," Industrial Marketing Management (40:7), pp. 1153-1159.

Naranjo-Gil, D. 2009. "The Influence of Environmental and Organizational Factors on Innovation Adoptions: Consequences for Performance in Public Sector Organizations," Technovation (29:12), pp. 810-818.

NSW Government. 2011. "Nsw 2012: A Plan to Make Nsw Number One," Department of Premier and Cabinet (ed.).

NSW SES. 2011. "Social Networking Policy." Wollongong, Australia.

NSW SES. 2016. "Annual Report 2015-16." Retrieved April 29, 2017, from https://www.ses.nsw.gov.au/media/1225/nswses_annual_report_2015_16_8mb.pdf

Oloruntoba, R., Hossain, G. F., and Wagner, B. 2016. "Theory in Humanitarian Operations Research," Annals of Operations Research), pp. 1-18.

Pan, G., Pan, S.-L., and Lim, C.-Y. 2015. "Examining How Firms Leverage It to Achieve Firm Productivity: Rbv and Dynamic Capabilities Perspectives," Information \& Management (52:4), pp. 401-412.

Pedraza-Martinez, A. J., and Van Wassenhove, L. N. 2016. "Empirically Grounded Research in Humanitarian Operations Management: The Way Forward," Journal of Operations Management (45), pp. 1-10.

Picazo-Vela, S., Gutiérrez-Martinez, I., and Luna-Reyes, L. F. 2011. "Social Media in the Public Sector: Perceived Benefits, Costs and Strategic Alternatives," 12th Annual International Conference on Digital Government Research (dg.o 2011), College Park, MD, USA: ACM, pp. 198-203.

Ponserre, S., Guha-Sapir, D., Vos, F., and Below, R. 2012. "Annual Disaster Statistical Review 2011."

Porter, M. E., and Millar, V. E. 1985. "How Information Gives You Competitive Advantage," Harvard Business Review (63:4), pp. 149-160.

Reuter, C., and Spielhofer, T. 2017. "Towards Social Resilience: A Quantitative and Qualitative Survey on Citizens' Perception of Social Media in Emergencies in Europe," Technological Forecasting and Social Change). 
Rogers, E. M. 2003. Diffusion of Innovation. New York: Free Press.

Rosenkopf, L., and Abrahamson, E. 1999. "Modeling Reputational and Informational Influences in Threshold Models of Bandwagon Innovation Diffusion," Computational \& Mathematical Organization Theory (5:4), pp. 361-384.

Samuel Fosso, W., Shahriar, A., Hyunjin, K., Mithu, B., and Mohammed, U. 2016. "The Primer of Social Media Analytics," Journal of Organizational and End User Computing (JOEUC) (28:2), pp. 1-12.

Sandsmark, F. 2011. "From Social Media to Social Commerce." Digital marketing

Scholl, H. J., Patin, B. J., and Chatfield, A. T. 2012. "Ict-Enabled City Government Field Operations: Resiliency During Extreme Events," 45th Hawaii International Conference on System Sciences (HICSS-45), Maui, HI, USA: IEEE, pp. 2346-2356.

Scott, S. G., and Lane, V. R. 2000. "A Stakeholder Approach to Organizational Identity," The Academy of Management Review (25:1), pp. 43-62.

Serafeimidis, V., and Smithson, S. 2003. "Information Systems Evaluation as an Organizational Institution - Experience from a Case Study," Information Systems Journal (13:3), pp. 251-274.

Steininger, D. M., Wunderlich, P., and Pohl, F. 2013. "Exploring Competitive Advantage of Social Networking Sites: A Business Model Perspective," in: 21st European Conference on Information Systems. Utrecht, Netherlands.

Stieglitz, S., and Dang-Xuan, L. 2013. "Emotions and Information Diffusion in Social Media-Sentiment of Microblogs and Sharing Behavior," Journal of Management Information Systems (29:4), pp. 217-248.

Sushil. 2017. "Theory Building Using Sap-Lap Linkages: An Application in the Context of Disaster Management," Annals of Operations Research), pp. 1-26.

Teece, D., Peteraf, M., and Leih, S. 2016. "Dynamic Capabilities and Organizational Agility: Risk, Uncertainty, and Strategy in the Innovation Economy," California Management Review (58:4), pp. 13-35.

Teodorescu, H.-N. 2015. "Using Analytics and Social Media for Monitoring and Mitigation of Social Disasters," Procedia Engineering (107), pp. 325-334.

Whetten, D. A. 2006. "Albert and Whetten Revisited: Strengthening the Concept of Organizational Identity," Journal of Management Inquiry (15:3), pp. 219-234.

Yates, D., and Paquette, S. 2011. "Emergency Knowledge Management and Social Media Technologies: A Case Study of the 2010 Haitian Earthquake," International Journal of Information Management (31:1), pp. 6-13.

Yin, R. K. 1994. Case Study Research: Design and Methods. Newbury Park, CA: Sage.

Yoo, E., Rand, W., Eftekhar, M., and Rabinovich, E. 2016. "Evaluating Information Diffusion Speed and Its Determinants in Social Media Networks During Humanitarian Crises," Journal of Operations Management (45), pp. 123-133.

Zaltman, G., Duncan, R., and Holbeck, J. 1973. Innovations and Organizations. New York: Wiley.

Zhu, K., Dong, S., Xu, S. X., Kraemer, K. L. . 2006. "Innovation Diffusion in Global Contexts: Determinants of Post-Adoption Digital Transformation of European Companies," European Journal of Information Systems (15), pp. 601-616.

Zhu, K., Kraemer, K., and Xu, S. 2003. "Electronic Business Adoption by European Firms: A Cross-Country Assessment of the Facilitators and Inhibitors," European Journal of Information Systems (12:4), pp. 251-268. 


\section{Appendix 1: Sample interview questions}

1. Please can you comment on NSW SES vision/strategy around social media tools adoption and use?

2. Please tell us about the organizational environment that brought about the need to adopt and use social media tools.

3. What are the objectives of the agency social media initiative?

4. Comment on the use by the NSW SES of the following social media tools (e.g., not aware of this, do not have, but aware, have but do not regularly use, have and regularly use for firm purposes):

- Facebook Company page; Facebook Group; Facebook Events Page; Twitter Channel; YouTube video/channel; Del.icio.us; LinkedIn; flickr; Other technology used (Please specify.

5. Please, can you comment on social media platform within the NSW SES (do you have integration of social platform with existing enterprise information systems?).

6. Do you take advantage of outside help to establish and/or maintain these tools?

7. Can you comment on the following dimensions related to social media adoption by the NSW SES

a. Level of use (internal and external),

b. Value/benefits (tangible and intangible),

c. Risks.

8. Can you comment on the types of interactions current used through social media tools by NSW SES with key stakeholders:

a. Volunteer (e.g., on the field, achievements, bond and identity to the NSW SES)

b. Citizen (e.g., information (type???)

c. Other agencies (e.g., collaboration, information sharing, coordination)

i. Management of comments (e.g., visibility, possibility to post and add, follow, etc.)

ii. Watching and listening to what fans or followers or members are posting

iii. Problem identification and resolution.

9. Can you comment on the role of senior management (e.g., support, understanding of importance of social media tools to support SES strategy) during the adoption process of social media tools?

10. Can you Comment on the future and importance of social media tools within the NSW SES? 


\section{Appendix 2: The NSW SES organizational chart}

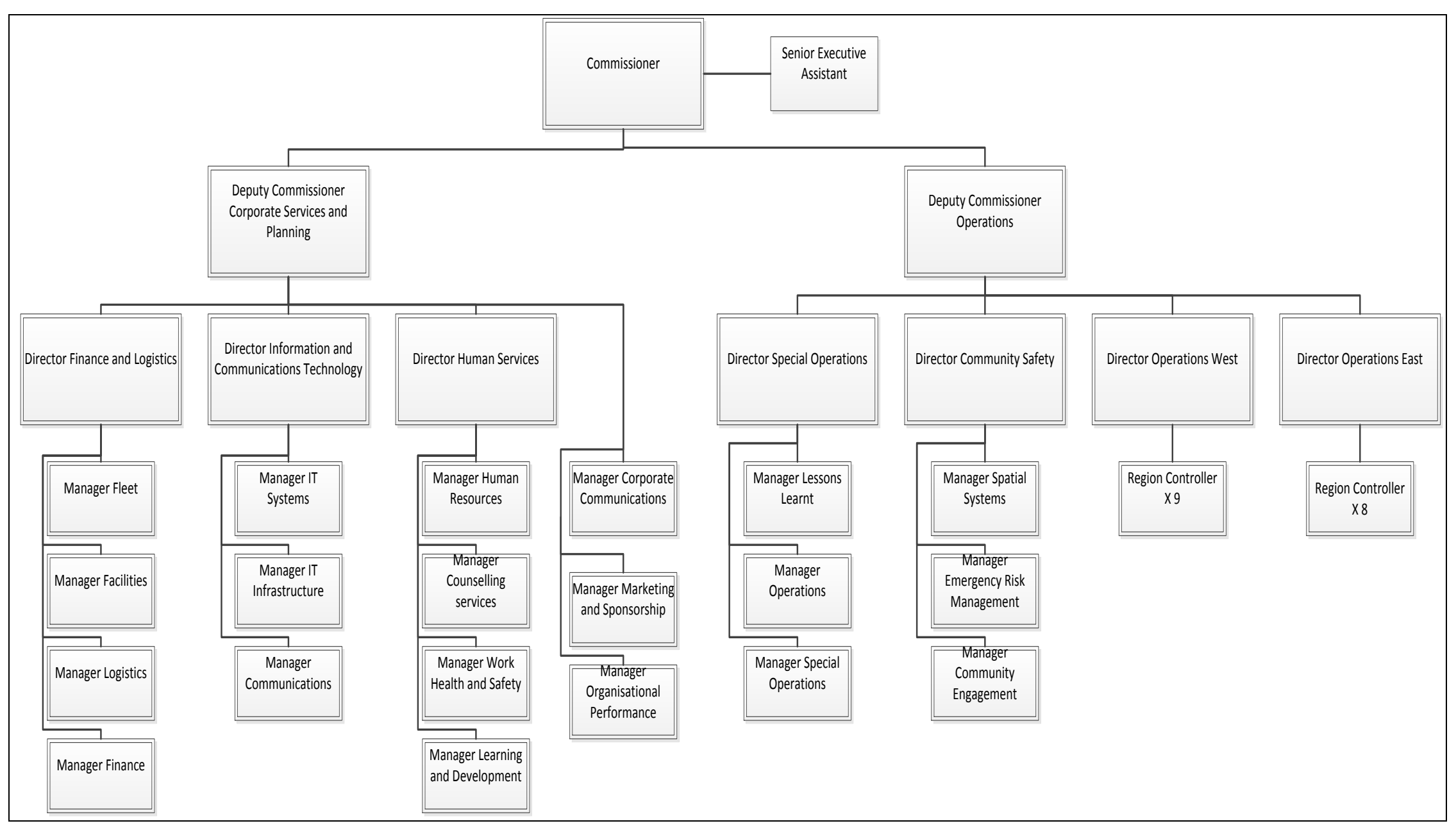

